\title{
Teachers' perceptions of the quality of the new Expressive Arts textbooks for Malawi primary schools
}

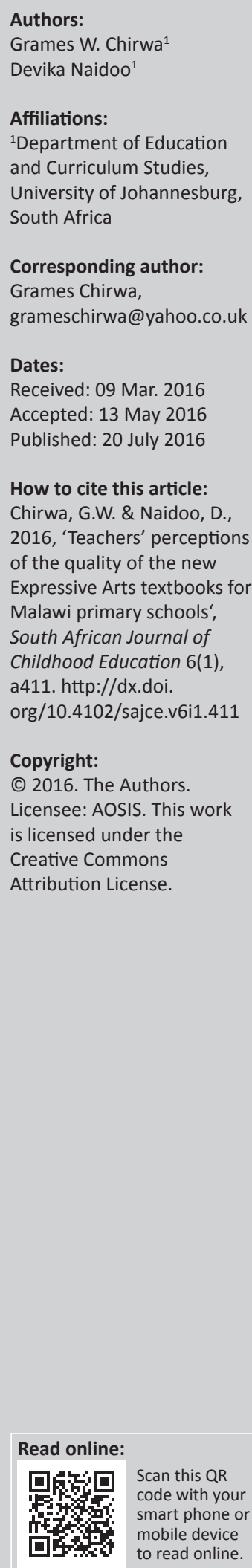

The national government in Malawi implemented an outcomes-based curriculum reform in 2007. To facilitate implementation, new textbooks were developed for the primary school curriculum. This study intended to explore teachers' use and perception of the new Expressive Arts textbooks. The participants consisted of 192 Expressive Arts teachers, grades $5-8$, selected by purposeful sampling. Data were collected through questionnaires and semistructured interviews. It was found that teachers believed that the textbooks were poorly designed, contained factual inaccuracies, did not support higher-level thinking of the learners, did not represent the lived experiences of the children using them and reinforced gender stereotyping. The study therefore suggests that there is need for review of the textbooks and that it is necessary to provide textbooks timely and in adequate quantities according to the needs of each school to ensure an effective implementation of a new curriculum.

\section{Introduction}

In its recent attempt to improve the quality of education in Malawi, the national government implemented an outcomes-based curriculum reform in 2007.

The adoption of an outcomes-based education curriculum in Malawi arose from regional influences, particularly the first Southern African Development Community (SADC) Protocol on Education and Training adopted in 1997. The protocol influenced the formulation of a new feature in South African education and curriculum landscape: an integrated qualifications framework (Chisholm 2005). By 2004, a number of SADC countries including Malawi formulated a curriculum with a strong vocational and training slant: an outcomes-based curriculum. The design features of the Malawi Outcomes Based Education have been influenced by South Africa's Curriculum 2005 (C2005) (Motara 2002). South African C2005 design itself has in turn been influenced by international curriculum ideas, particularly Spady's (1994) transformational Outcomes Based Education (OBE) and Canadian and Australian curricula (Motara 2002). The characteristic features of Ontario's 'The Common Curriculum' in Canada are 'essential learning outcomes and integration of traditional subjects'.

The new curriculum was also meant to diversify and make the curriculum more practical and relevant to Malawi's socio-economic needs, which include the change from a single to a multiparty system of government; rapid population growth; HIV and/or AIDS pandemic; gender disparity; and environmental degradation (Khomani 2005). Every new curriculum innovation adopts its own new instructional materials. Thus, the old instructional materials become dysfunctional and redundant. New material which was unfamiliar to the implementer reduced the effectiveness of the implementation.

As part of the implementation, the Malawi Ministry of Education through the Malawi Institute of Education (MIE), the national curriculum development centre in Malawi developed instructional materials for the primary school curriculum. The instructional materials include syllabuses, teachers' guides and learners' textbooks for different subjects (Khomani 2005).

This article is based on an empirical study which sought to investigate teachers' perceptions of the quality of textbooks for grades 5-8 Expressive Arts curriculum in Malawi primary schools.

Expressive Arts is one of the nine subjects in the 2007 national curriculum. It is an integrated curriculum using themes such as body movements, conveying cultural messages, multi-cultural performances and dances to integrate across multiple subject disciplines such as creative arts, physical education, music, drama and needlecraft.

Note: Some of the research and writing of this article is based on work previously published by the authors. Please see doi: 10.5901/ mjss.2014.v5n16p261 
Instructional materials for Expressive Arts were not field tested as is normally the practice in curriculum development. Field testing and revision of new instructional materials form part and parcel of the entire process of curriculum development. It was planned that the instructional materials would be developed and sent to the schools prior to implementation, where they would be implemented for two to three years as part of nation-wide field testing and later be revised. Apparently, this arrangement did not happen. Consequently, at the time of this study, the instructional materials had been used for more than three years without review.

This study was, therefore, designed to solicit teachers' views in relation to grades 5-8 instructional materials after using them for some time. The findings of this study will inform curriculum developers, educationists and policy makers on areas that need revision in the instructional materials. This would facilitate provision of pedagogically sound instructional materials to primary schools in Malawi.

Teachers' perceptions influence teachers' practice, judgement and decision making (Barcelos 2003; Pederson 2003). Teachers play a key role in learning and teaching; therefore, it is believed that investigating teachers' perceptions will uncover salient shortcomings occurring in educational settings which will be invaluable to teachers' educational development. However, it has been noticed that there has been little explicit research focusing on teachers' perceptions of the quality of textbooks (Barcelos 2003).

To date, Expressive Arts textbooks, just like the textbooks of all the other eight subjects in the new curriculum in Malawi, have not been benchmarked. Therefore, the researchers were interested in exploring teachers' perceptions of the quality of Expressive Arts textbooks and identifying problems experienced by teachers while using the textbooks.

The article has thus a potential to contribute to knowledge in the education sector in Malawi and the SADC region on what the basic attributes of good textbooks in a country should be.

\section{Conceptual framework}

This study was informed by the theories of course book assessment as postulated by Ur (1998) and basic attributes of good textbooks as postulated by Abadzi (2006). These authors have suggested a yardstick for evaluating the quality of textbooks. Ur (1998) has proposed the following yardstick for evaluating the quality of textbooks: user-friendliness of the instructional materials in terms of clarity of instructions for activities; appropriateness of level of language in relation to learners' intellectual ability; appropriateness of suggested teaching, learning and assessment methodologies and resources; and clarity of illustrations and their ability to support text.

Abadzi (2006) has suggested some of the basic attributes of good textbooks. This author states that good textbooks should have serious focus on content, with rich and extensive explanation and elaboration of concepts. Secondly, there should be extensive use of pictures, drawings, diagrams and figures that capture the essence of important concepts. The pictures should not just be cartoon drawings of figures with bubble instructions or arbitrary images of some event, but rather skilled pedagogic distillations of the essential patterns, relationships and logic of a specific content area (p. 91). Thirdly, there should be ample space for practice and elaboration that enables graded upward progression. This can be provided either in the textbook or in an attached workbook. Fourthly, the textbook topics should be efficiently and clearly organised and they should be simple to read, with uncluttered layout that foregrounds meaning.

Fifthly, clear and explicit structural links should be made with the material already covered and should take learners through increasing levels of difficulty, elaboration or focus (Abadzi 2006:91).

\section{Literature review}

It has been widely accepted that textbooks play a crucial role in classrooms (Richards 2001). The use of textbooks assists in the implementation of curriculum reforms. According to Lukin (2004), to maximise student learning, three critical elements must be in place. Firstly, there must be a clearly articulated curriculum. The secondly element that must be in place is the delivery of this curriculum through appropriate and effective instructional materials. Thirdly, appropriate classroom instructional and assessment practices must be implemented. It is the second element, the appropriate and effective instructional materials for maximising student learning in Expressive Arts that is the focus of this article.

There is no doubt that appropriate and effective instructional materials, particularly textbooks, play a central role in many educational efforts. It has been noted, for example, by Hugo et al. (2008) that if we are interested in positively influencing the teaching-learning process in the classroom, we may have to start with production and provision of appropriate and effective instructional materials. Hugo (2006) has argued that the textbook is the learner's take-home resource that extends learning beyond the classroom; it supports the teacher who is unsure of a particular section; it structures the work of the year into a coherent whole that builds on the previous year and prepares for the next one. According to Hugo (2006), good textbooks for all are one of the cheapest and most effective ways to get quality into the classroom and the home. Hutchinson and Torres (1994) believe that the prominence of textbooks is so expansive that it is almost a universal element in classrooms. They further claim that any teaching and learning situation will not be complete unless it has its relevant text books. Ur (1998) points out that textbooks provide explicit frameworks which provide guidelines for teachers and learners as to what they have done and what will be done. Moreover, she reports that textbooks are the cheapest tools compared with other materials such as learning kits, photocopied worksheets or computer software. 
O'Neil (1982), Sheldon (1988) and Ur (1998) agree that textbooks are efficient teaching materials which save both time and money. They clarify that textbooks can reduce time in material preparations so that teachers can devote more time to teaching instead of spending time with creating inhouse materials. In addition, textbooks are effective teaching and learning resources for teachers and learners because they are presumably products of experienced researchers and developers (Hammer 2001).

Many researchers, on the contrary, emphasise the limitations of textbooks. For example, Ur (1998) mentions that textbooks are inadequate for supplying every learner's needs. Moreover, most topics in textbooks have been found to be irrelevant or uninteresting to learners and the cause of boredom and paucity of motivation. Textbooks may hinder a teacher's initiative and creativity because of its set structure and sequence. Besides, Richards (2001) states that some textbooks may not suit all learners' needs because they are often written for global markets. Sheldon (1988) adds that textbooks may be worthless and can be seen as a poor compromise between what is educationally desirable on the one hand and financially viable on the other.

Good textbooks however can contribute to student learning. Abadzi (2006) argues that textbooks are a key resource and high quality of textbooks is non-negotiable. Textbooks should be rated by experts through a process that is beyond corruption, well structured and well rewarded. To counteract fraud in textbook rating or evaluation, there should be more than one textbook evaluation committee. Senegal has two textbook evaluation committees for each textbook, in order to counteract corruption issues (Abadzi 2006).

Similarly, Fredricks (2005) has also argued for the importance of textbooks in classrooms. According to this author, textbooks that are carefully written and designed, professionally edited and tested, offering not merely factual information but also interactive spaces for children are important and have several advantages in the classroom. Some of these advantages are: firstly, they are helpful to teachers. This is because the material to be covered and the design of each lesson are carefully spelled out in detail. Secondly, textbooks provide organised units of work. A textbook gives the teacher all the lessons that need to be covered on a topic in some detail. Thirdly, a textbook series provides one with a balanced, chronological presentation of information. The following characteristics of good textbooks are provided: They are usually well organised, coherent, unified, relatively up-to-date, accurate, and fairly unbiased. They have been scrutinised by scholars, educators and minority groups. Their reading level and knowledge base match the developmental level of their intended audience. They are accompanied by teacher's manuals, test items, study guides and activity guides (Fredricks 2005).

However, Fredricks (2005) warns that as good as textbooks may appear on the surface, critics have found that textbooks, in nearly every subject and grade level have some limitations. For example, they cover too many topics; the writing is superficial and lacking in-depth and breadth.

As with many textbooks around the globe, as argued by Fredricks, textbooks developed in Malawi also have limitations. For example, a study by Sailors (2012) shows that most instructional materials developed in Malawi do not have the basic attributes of good or high-quality textbooks as described by Abadzi. Sailors (2012) has argued that most instructional materials that support the new curriculum in Malawi are not properly designed, with information errors and content promoting gender bias. Similarly, Muhamad (2009) conducted a research with English teachers to investigate their perceptions of English textbooks. The findings revealed that teachers concluded that textbooks could not serve teachers' and learners' needs because they lacked content appropriateness. Again, Chandran (2003) did a study of Malaysian teachers' perception of English textbooks. The study showed that teachers did not use the prescribed textbooks because the textbooks did not expose their learners to examination-type questions.

\section{Context and background Materials development}

The MIE, the national curriculum development centre in Malawi, followed a curriculum development process in which classroom teachers served as authors of the textbooks. The books were developed in a writing workshop at the MIE. In-service and pre-service primary school teachers; Ministry of Education, Science and Technology officials; teacher training lecturers; and MIE's curriculum specialists responsible for music, needlecraft, creative arts, physical education, drama and dance were trained and learnt how to write instructional materials that focus on connecting or integrating these subject areas to form Expressive Arts. The authors used the instructional materials of the former curriculum for the previously stand-alone subjects of music, needlecraft, creative arts, physical education, drama and dance as a basis for the books. The images or illustrations for the instructional materials were developed and designed by local artists. The images or the illustrations were in black and white (not in colour) (Khomani 2005).

After the development of the textbooks, the government devised a new strategy to minimise the problem of distribution of books and other educational materials to schools for the implementation of the new curriculum. It is however not clear whether this new strategy solved the problem of distribution of books which has been there for many years in Malawi. The current study also set out to collect such information.

Distribution of books and other educational materials has been a problem in Malawi for many years. Books in the past have been stacked in regional or district education offices while schools had serious shortages of books. The problem 
was the lack of transport to deliver the materials to schools. In order to hasten the implementation of the new curriculum, a new scheme was devised for book distribution to schools.

Currently, publishers or printers of the new materials deliver the books to the supplies unit which sends the books to the regional offices. Books are then sent to district education offices for distribution to schools. Where problems of transport exist in district offices, tenders were issued to private transporters to deliver the books to schools. The transport scheme however has a problem because a number of remote schools are inaccessible with any type of vehicle. It is not clear how this will be resolved. Studies by Chimombo (2005) and Nsapato (2005) show that primary schools in Malawi face serious shortage of instructional materials that affect the effective implementation of the school curricula. These authors argue that Malawi has the lowest percentage of the availability of textbooks for both teachers and pupils in the sub-Saharan region. This view point that Malawi faces instructional materials resource constraints are confirmed by Lowe's (2008) and Kadzamira's (2006) studies. Lowe and Kadzamira found that lack of learning resources, especially textbooks, affects the successful implementation of a curriculum in Malawi. Lowe found that there was high pupil to text book ratio in the schools involved in his study. Kadzamira noted that the primary school system in Malawi lacks teaching and learning materials, especially the rural primary schools.

\section{Research methodology}

The main purpose of this study was to explore teachers' perceptions of the quality of the Expressive Arts textbooks and the problems raised by teachers in the course of using them. To achieve this purpose, a mixed method research with greater emphasis on qualitative approach was employed.

The design of the study was based on the premise that understanding the functioning of the primary school instructional materials requires getting primary school teachers' voices as the implementers of the curriculum.

\section{Participants}

This study was conducted with 192 Expressive Arts teachers belonging to grades $5-8$. The participants were from two government schools from each of the six education divisions in Malawi.

The study was designed in such a way that its sample was drawn from all the six education divisions of the country, namely Northern Division, Central East Division, Central West Division, South East Division, South West Division and Shire Highlands. Data were collected from one zone within sampled districts in each division.

In each district, a township school and a rural school were selected for the study. In each of the selected schools, four teachers were invited to a Teacher Development Centre
(TDC) to form part of the sample. The four teachers were from each grade (grades 5-8).

\section{Instrumentation}

The teachers from grades 5, 6, 7 and 8 participated in two major activities during the data collection exercise. They completed a questionnaire in pairs by standard and later the four teachers per standard participated in a focus group discussion. These data collection instruments are discussed in detail below.

\section{The questionnaire}

The questionnaire was the primary source to find teachers' perceptions. It aimed to elicit an overview of teachers' perceptions of the quality of the Expressive Arts textbooks. It consisted of two parts which allowed teachers to share their beliefs, attitudes and opinions that reflected their perceptions. The first part of the questionnaire tended to ascertain the background information of the teachers. The latter part included items aimed at eliciting teachers' perceptions of the quality of the textbooks.

This tool was administered to teachers of each grade. The four teachers for each grade collaborated in completing the questionnaire. Using the questionnaires, the teachers provided data pertaining to the issues of relevance and adequacy of the content in the instructional materials; user-friendliness of the instructional materials in terms of clarity of instructions for activities; appropriateness of level of language in relation to learners' intellectual ability; appropriateness of suggested teaching, learning and assessment methodologies and resources; and clarity of illustrations and their ability to support text.

\section{Semi-structured interview}

The semi-structured interview through focus group discussion was employed to seek further information. The data obtained from interviews provided deeper answers and cross checked accuracy of the questionnaire data. All open-ended questions were derived from the aforementioned literature review and the purposes of the study. The questions aimed at gaining indepth data about teachers' perceptions of the quality of the Expressive Arts textbooks.

\section{Data analysis}

A qualitative analysis was conducted for the data from the questionnaire, and the semi-structured interviews, which were aimed at gaining insight into teachers' perceptions of using the Expressive Arts textbooks and to identify problems teachers rose about using the textbooks. The findings were analysed using the following themes, which were adapted from Ur's (1998) criteria for course book assessment; perceptions towards using textbooks in their teaching; user-friendliness of the instructional materials in terms of clarity of instructions for activities; appropriateness of the level of language in relation to learners' intellectual ability; appropriateness of suggested 
teaching, learning and assessment methodologies and resources; and clarity of illustrations and their ability to support text.

\section{Findings}

The following were the findings of the study.

\section{Teachers' perceptions towards using textbooks}

The interview data indicated that teachers regarded textbooks as an important or valuable instructional framework because textbooks assisted them in preparing lessons. In addition, they considered textbooks as guidelines for them about how lessons can be delivered. They further stated that textbooks were effective teaching materials which served them both time and money. Teachers also indicated that textbooks helped them save time in teaching preparation because textbooks provided detailed activities and exercises. Teachers indicated that they were assigned to undertake extra duties other than their daily instructions. Consequently, the teachers considered using textbooks as the best way to reduce their workloads. Furthermore, teachers pointed out that textbooks were reliable and effective teaching materials because they have been tried, tested and developed by curriculum specialists and experts. In this light, they felt confident to use textbooks as their source of teaching.

Some teachers explained that they sometimes used other teaching materials to supplement their teaching. Nevertheless, they said that their teaching would be very difficult without textbooks and they preferred using textbooks to other teaching materials.

\section{Adequacy and relevance of content for senior primary schools in Malawi}

The majority of the teachers indicated that the textbooks lacked specification of knowledge. They indicated that although they tried their best to look for information from other sources, they were not able to find the information. The teachers indicated that the lack of specification of knowledge in the textbooks made teaching and learning ineffective because both the teachers and the learners ended up not having adequate knowledge of the subject matter the teachers had to teach. The teachers indicated that they were teaching just to fulfil the requirements of their job.

An analysis of the grade 8 textbook confirmed the teachers' claims of lack of specification of knowledge in the textbook. For example, the 'Introduction' section of topic 4, on 'Tempo and dynamics in traditional and contemporary music', presented below lacks specification of knowledge:

Different songs have different tempos depending on the messages they are giving. The tempos of different cultural songs and dances will vary according to different occasions during which the dances and songs are performed. Dynamics refer to the degree of loudness and softness of sound in a piece of music.
Dynamics in a piece of music are shown by using marks such as $\mathrm{f}$ (forte) or $\mathrm{p}$ (piano). These marks are put at the beginning of a piece of music or at any appropriate place in the piece of music. (Malawi Institute of Education 2008a)

An analysis of the teaching and learning activities for this topic, 'Tempo and dynamics in traditional and contemporary music' require the teachers to discuss with the learners the following tempos and dynamic terms: 'andante', 'adagio' and 'allegro'. However, the content knowledge in the introduction of the topic does not include an explanation of the meaning of these terms. In the textbook, the learners are expected to be taught and learn these terminologies. Based on the above example, the teachers' complaint about superficial presentation of content in the instructional materials may be understandable.

Similarly, the teacher's complaint about the instructional materials is also confirmed by the section from the grade 7 textbook (Figure 1).

An analysis of the teaching and learning activities for this topic 'mirroring' presented above require the teachers to discuss with the learners the skills of a lay-up shot in basketball and tennis serve. However, the content knowledge does not include a description of the skills of a lay-up shot

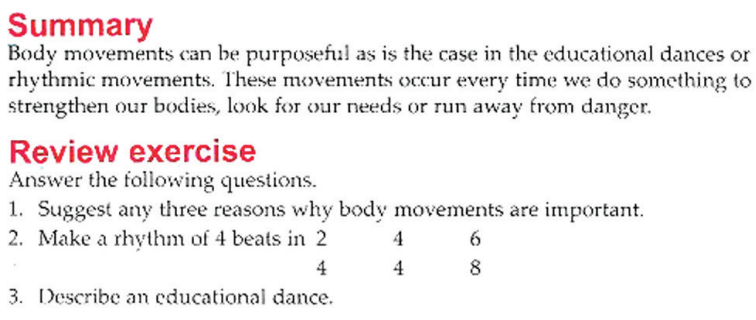

\section{Topic 2 Mirroring}

\section{Introduction}

You are said to be doing mirroring activities when you copy, as closcly as possible, the actions, words, or expressions of another person. It is a common technigue in physical activities, especially when your teacher wants to teach you a new movement such as a dance step, a lay up in basket ball, a tennis serve, or running activities. Mirroring can also be used to learn attention skills, such as in an improvised movement which classmates can then copy or mirror.

\section{Activities}

Activity 1 Naming and discussing mirroring activities (1 period) Instructions

1 Study the illustrations below.

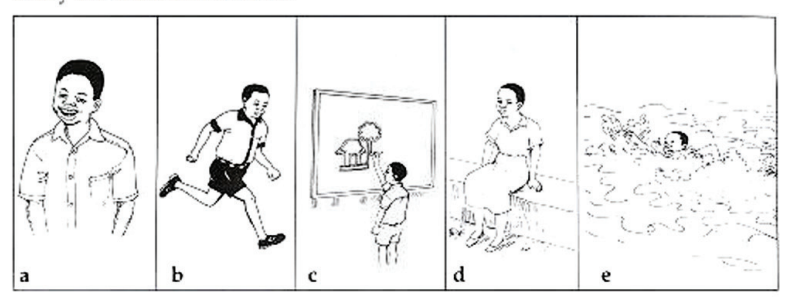

2 Discuss what you see in the il]ustrations.

3 Name the activities that can be mirrored.

4 Discuss how the mirroring activities which you have named above are done. 8

Source: Malawi Institute of Education, 2008a, Expressive Arts learners' book for standard 7 Malawi Institute of Education, Domasi

FIGURE 1: Teacher's complaint about the instructional materials is also confirmed by the section from the grade 7 textbook. 
and a tennis serve. According to the textbook, the learners are expected to be taught and learn these skills. Based on the above example of how content is presented in the Expressive Arts textbooks, the teachers' complaint about superficial presentation of content in the instructional materials may be understandable. However, this does not rule out the possibility that the teachers do not seem to be creative and resourceful enough in sourcing information not available in the instructional materials to make the teaching and learning of Expressive Arts more effective.

In addition to superficial presentation of knowledge in the textbooks, most of the teachers noted that the textbooks have factual inaccuracies. An analysis of the textbooks confirmed this. For example, the following information from grade 7 Expressive Arts textbook on the topic, 'Mirroring' present factual inaccuracies:

You are said to be doing mirroring activities when you copy, as closely as possible, the actions, words, or expressions of another person. It is a common technique in physical activities, especially when your teacher wants to teach you a new movement such as a dance step, a lay up in basket ball, a tennis serve, or running activities. Mirroring can also be used to learn attention skills, such as in an improved movement which classmates can then copy or mirror. (Malawi Institute of Education 2008b)

In the extract above, the examples given as mirroring activities, a lay-up in basketball, a tennis serve, or running activities are not correct. In physical education, mirroring activities are 'aerobics' as they are performed by copying the actions of another person, an instructor specifically.

Again, in addition to factual inaccuracies in the textbooks, most of the teachers also noted that the organisation of the content in the textbooks is inappropriate. The teachers cited the order of the content in the physical education component in the Expressive Arts textbook as inappropriate. They indicated that the chronological order of the content does not coincide well with the seasons of the year; hence, some activities that are supposed to be done outdoors coincide with the rainy season. For example, the order of the topics to be taught in the Expressive Arts makes the teaching of the outdoor games, such as 'football' and 'netball' to fall in the rainy season. As the schools in Malawi do not have gymnasiums, it is difficult to teach this content during the rainy season. When probed further about their creativity so as for them to try to shuffle the order of the content around to have the games taught during the suitable and appropriate time of the year, the teachers indicated that the education system in Malawi expect them to stick to the syllabus both in terms of the content they are teaching and its chronological order, failing which they would lose their jobs, if found 'not sticking to the syllabus' by their supervisors, the primary education advisors.

In addition to the inappropriate sequencing of the content, the majority of the teachers also indicated that there is too much content to be covered in a year compared with the actual learning time available in a school year. The teachers further pointed out that there is a mismatch between the time suggested for the learning tasks or activities in the instructional materials and the demands of the tasks or activities. For example, the teachers argued that instructional materials have suggested more time for teaching and learning for activities which in reality did not require too much time, as is currently the case in the instructional materials.

An analysis of the textbooks confirmed the teachers' assertion. For example, topic 1 in the Grade 8 textbook which is on 'Artistic Creativity' has been allocated 7 periods of 35 minutes each for teaching while topic 7 which is on 'Cultural dances' has been given 32 periods for teaching. In reality, activities involving the learners to create art items and activities would need more time than just dancing. Literature on arts education internationally advocates experiential learning. For example, Kolb (1994) suggests that experiential learning for arts education should be based on concrete experience through active experimentation by the learners, which can be provided through a range of pedagogical strategies, including simulations, informal learning through small and large group discussions, and reflective practice exercises and activities. Thus, arts education pedagogy differs from other subjects in that it emphasises experiential learning through multimodal activities. The teachers' concern that there is inappropriate allocation of time to activities in the textbooks may thus be justified.

The teachers also observed that some of the learning activities in the instructional materials are not familiar to most of the teachers, for example, the topic on sewing 'Magyar' dress, making the teaching and learning difficult. The topic 'Magyar' dress in the grade 7 textbook, like many other topics in the Expressive Arts textbooks, lacks specification of knowledge to enable the learners study on their own at home for example.

\section{Appropriateness of the language to the learners' intellectual ability}

The majority of the teachers observed that some of the words used in the textbooks are difficult and inappropriate for the level of primary school learners, especially since not all of the difficult words are included in the glossary of difficult words for each topic. The majority of the teachers cited works like 'stuffing' and 'Magyar' dresses in the needlecraft component of Expressive Arts and 'dribbling' in the physical education component of the Expressive Arts textbooks. The teachers also observed that there is no glossary for difficult words in other topics in the instructional materials, and in instances where there are, not all difficult words in the topic were defined, described and explained. This shows inconsistency in the presentation of the material, and this may be considered a sign of poor design of the instructional materials.

\section{Clarity, relevance and illustrations and their ability to support text}

The majority of the teachers observed that the illustrations in the instructional materials are inaccurate and they do not 
support the instructional materials in terms of clarifying the content. The teachers indicated that most of the illustrations do not represent the ideas they are supposed to. For example, the teachers indicated that illustrations that were meant to represent some of the various cultural dances performed in some provinces in Malawi are inaccurate as they do not represent those dances correctly. The teachers further observed that most of the illustrations were not clear, particularly because they are not in colour and most of them do not support the text.

Most of the teachers also observed that some of the illustrations or pictures are not suitable for primary school learners as they can easily reinforce bad behaviour, such as sexual immorality on the part of the learners, as learners at primary school level are highly impressionable and they can easily start imitating the behaviour depicted in the illustrations, pictures or the cartoons. The teachers further observed that some of the pictures or illustrations for certain topics are gender stereotyped. For example, the teachers cited pictures on topics like knitting and sewing, in which the pictures or the cartoons give an impression that knitting and sewing are girls' activities.

Presented below is a copy of illustration (a) in the grade 7 Expressive Arts textbook which teachers complained of being inaccurate.

For illustration (a), the teachers commented that the illustrators may have had in mind the 'Vimbuza' dance of the northern region of Malawi, which they wanted to depict. However, the illustration shows that the dance was inaccurately depicted and for this reason, the teachers feel that the illustrations in the textbooks are inaccurate and they do not represent the ideas they were meant to represent correctly (Figure 2).

\section{Appropriateness of the teaching, learning and assessment resources in the instructional materials}

The majority of the teachers indicated that some of the teaching and learning resources in the instructional materials suggested for use by the teachers are not familiar to the teachers. Teachers are not familiar with resources such as Braille Paper and Raised Diagram. Further, most of the teachers indicated that other teaching and learning resources which have been suggested in the instructional materials cannot be easily found within the localities of the schools. The teachers cited 'flutes' for the dance component of the Expressive Arts as not easy to find locally within the environs of most of the schools. For this reason, the teachers indicated that the instructional materials for Expressive Arts lack relevancy to the Malawian education context.

However, the teachers indicated that the teaching, learning and assessment methodologies suggested in the instructional materials are appropriate as they are varied and this gives a

\section{UNIT 4 Multi-cultural performance}

\section{Topic 1 Artistic activities from various cultures in Malawi}

\section{Introduction}

Malawi has many ethnic groups and each has different cultural practices. Examples of such practices include folkdances and songs. Folkdances and songs serve as an identily of a particular culture and are passed from one generation to another.

Activities

Activity 1 Discussing folkdances from various cultures in Malawi

Instructions

1 Study the illustrations below

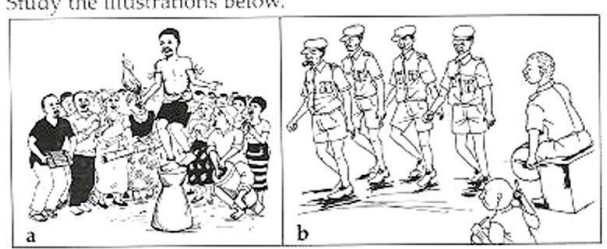

2 State the type of folkdances shown in the illustrations and where they are pertormed.

Discuss other folkdances you know and the ethnic groups that perform them.

4 Discuss the musical instruments, organisation of the dances, dancing styles and costumcs used in the dances.

Discuss the significance of the dances to those cultures.

Perform some of the folkdances mentioned.

7 Comment on your friends performance

Activity 2 Singing songs depicting cultural practices

Instructions

1 Discuss cultural practices in your area and from other cultures in Malawi.

Compose songs about some of the cultural practices.

[ractise singing the composed songs.

Source: Malawi Institute of Education, 2008b, Expressive Arts learners' book for standard 8 Malawi Institute of Education, Domasi

FIGURE 2: Teachers feel that the illustrations in the textbooks are inaccurate and they do not represent the ideas they were meant to represent correctly.

wider choice or options and flexibility to the teachers to vary their methods of teaching and assessment of the learners according to the situation at hand in the classroom. When probed further for them to shed more light on what they indicated that the teaching, learning and methods were varied, the teachers mentioned methods like role-play and practical as varied methods provided in the instructional materials.

However, the teachers indicated that although a variety of teaching and learning methods have been suggested in the instructional materials, the challenge is that the instructional materials have over-emphasised discussion as a method of teaching and learning in the new curriculum. The teachers observed that this method does not work well in the Malawian context because of the limited English vocabulary of the learners which hinders their ability to express themselves fluently, which in turn prevents them from discussing a given task. When the teachers were probed further about the assessment methods and resources provided in the instructional materials which they considered varied, they made a mention of peer-assessment, selfassessment and use of the checklist and rubric. However, the teachers noted that the only challenge with the assessment tasks in the instructional materials is that the review questions 
which have been provided at the end of each topic are mostly recall questions, requiring memorisation of information on the part of the learners, and this cannot promote higher-level thinking of the learners. The teachers also indicated that the number of question items for the review exercises are not even enough, usually only two questions covering a long topic. In addition to inadequate questions for the review exercises, the teachers observed that the instructional materials did not have model answers to the review questions. The teachers further noted that the summaries at the end of the topics did not have enough or adequate information to provide a helpful or effective synopsis of the topic learned.

This means that the learners cannot have an adequate revision of the topic covered. For this reason the majority of the teachers consider the content of the instructional materials, especially the learners' book inadequate.

In terms of the appropriateness of the teaching and learning resources suggested in the instructional materials, most of the teachers indicated that although the instructional materials suggest a variety of teaching and learning resources for teaching a certain topic or content knowledge, the challenge however is that most of the suggested teaching and learning resources are difficult to find locally. The teachers noted that some of the resources for some topics or content to be taught cannot be substituted as doing so will negatively affect the effective teaching of such topic or content. The teachers thus suggested that the government should provide those resources which are difficult to find locally.

\section{Discussion}

This study has established that Expressive Arts textbooks in Malawi have some limitations. In this study, the teachers pointed out that the level of learners' language proficiency did not match with the level of language input in the textbooks. These findings are supported by the views of Richards (2001) and Ur (1998). They assert that textbooks cannot meet the varied language needs of learners around the world. The study further found that the Expressive Arts textbooks are poorly designed. The teachers felt that the content or the topics in the instructional materials are not properly arranged or sequenced to link them to the environment in Malawi, for example the climatic seasons of the country. The teachers also indicated that there is superficial coverage of knowledge in the instructional materials. Furthermore, the teachers observed that the illustrations in the instructional materials are inaccurate. They are not correct in what they were intended to represent in reality. In this regard, Sailors (2012) found that the instructional materials developed in Malawi are not properly designed, the information in them is full of errors and they promote gender bias. Similarly, Hugo et al. (2008), observed that the instructional materials for basic education in South Africa are of poor quality as they do not meet the basic attributes of high-quality instructional materials as described by Abadzi (2006). Hugo argues that the instructional materials for basic education in South Africa also contain a lot of factual inaccuracies.

In addition to what can be considered or regarded as 'direct problems' of the Expressive Arts textbooks, problems relating to the limitations of textbooks, the study also uncovered what can be considered or regarded as 'indirect problems'. Indirect problems may refer to problems occurring due to factors other than textbooks themselves but which present hindrance to the teachers and the learners' utilising the textbooks effectively.

The first indirect problem uncovered by the study is that teachers revealed most of their learners had poor English proficiency. This was a serious hindrance to utilising the textbooks effectively by the learners. Furthermore, teachers asserted that having large classes affected the use of the textbooks. They indicated that activities which suggested assigning learners to have pair work and group work were not suitable for large classes because every learner could not be monitored.

The third indirect problem uncovered by this study relates to teaching children with special education needs using the textbooks. The study found that teachers were not oriented to the use of teaching the resources suggested in the textbooks for teaching children with special education needs, especially those with physical challenges. This was evidenced from the teachers' lack of knowledge of the meaning of Braille paper and Raised Diagrams. This article proposes that teachers need to be oriented to the resources for teaching education special education needs as not all special needs children go to Special Needs Education institutions. Many of them are main streamed in the ordinary state schools.

The fourth indirect problem uncovered by the study is that teachers are not given adequate orientation to the new instructional materials, especially those aspects or content which may not have been there in the previous or the preceding curriculum.

The fifth indirect problem uncovered by the study is that the main challenge when the new curriculum was introduced in Malawi was the provision of new instructional materials. The study uncovered that support instructional materials for the new curriculum were not provided to the schools prior to implementation of the new curriculum and in cases where the new instructional materials were provided to the schools, they were often insufficient or not in enough quantities to match with the enrolment or the number of children in a given school. This finding confirms UNESCO's (2000) observation that instructional materials are not readily available in developing countries. Similarly, Jansen (1998) noted that there were uneven distribution of instructional materials and other OBE-related resource materials in the South African schools and classrooms which he visited during his study period to evaluate the implementation of C2005. Jansen's study established that the variations in the availability of the various 
OBE-related teaching and learning materials in the schools affected the way the teachers were implementing the curriculum. The study found that some teachers and schools which had been supplied with materials in the early part of the year when the OBE curriculum was being implemented were more closer to implementing the curriculum in the way they were expected to do compared to those teachers and schools which had been supplied with the materials later in the year in which the OBE curriculum was implemented. The variations in the availability of materials may probably have been a contributing factor to the differences among schools in the implementation of the curriculum. Luykx (1999) found that Bolivia, a developed country, also faced serious shortages of instructional materials similar to the findings of this study that there are serious shortages of instructional materials in Malawi. Again, as in this study, Chimombo's (2005), Nsapato's (2005), Lowe's (2008) and Kadzamira's (2006) also found that Malawi has the lowest percentage of the availability of textbooks for both teachers and pupils in the sub-Saharan region and that the primary school system in Malawi lacks teaching and learning materials, especially in the rural primary schools, which affect the successful implementation of the primary school curriculum.

This article therefore proposes that it is important that when planning for curriculum innovation, the government should ensure that new relevant support instructional material is developed and where possible distributed to schools prior to implementation of the new curriculum.

The sixth indirect problem uncovered by this study is that teachers depend solely on the textbook as the only resource for teaching the new curriculum, of which the teachers indicated that they do not have sufficient information. This article thus proposes that the government needs to provide the teachers with other reference materials relevant to the new curriculum and/or the teachers themselves need to be active enough to consult other reference materials rather than solely depend on the support instructional materials for the new curriculum provided to them by the state.

\section{Conclusion}

The present study intended to explore teachers' perceptions about Expressive Arts textbooks which they are using, and explore the problems of the textbooks raised by teachers. The findings of this study revealed that teachers believed that textbooks were essential and teaching cannot be conducted effectively without the use of textbooks. Some of them also revealed that textbooks should go hand in hand with supplementary teaching materials to serve the learners' needs. The results of the study further revealed that problems about using the Expressive Arts textbooks were inherent in the textbooks themselves, learners' language proficiency not matching with the level of language input in the textbooks. The Expressive Arts textbooks are poorly designed. The content or the topics in the instructional materials are not properly arranged or sequenced to link them to the environment in Malawi. There is superficial coverage of knowledge in the instructional materials. The illustrations in the instructional materials are inaccurate.
The study therefore suggests that there is need for review of the Expressive Arts textbooks and that it is necessary to provide the textbooks timely and in adequate quantities according to the needs of each school to ensure an effective implementation of a new curriculum. In addition to this, the study also suggests teachers need to be trained on how to use the new textbooks effectively.

\section{Acknowledgements}

The contributions of those who spent both time and effort to participate in this study are particularly highly valued. These participants are mainly the teachers of Expressive Arts teaching grades 5-8 in Malawi primary schools and those who granted access to the schools for the study. In terms of the latter, officials from division and district offices of the Ministry of Education were especially helpful.

\section{Competing interests}

The authors declare that they have no financial or personal relationships which may have inappropriately influenced them in writing this article.

\section{Authors' contributions}

G.W.C. was responsible for collecting data on the perceptions of teachers on the quality of Expressive Arts textbooks with the Malawi Institute of Education. D.N. made conceptual contributions to the drafting and final production of this journal article.

\section{References}

Abadzi, H., 2006, Efficient learning for the poor, World Bank, Washington, DC. Barcelos, A.M.F., 2003, Researching beliefs about SLA: A critical review, Kluwer Academic Publishers, Dordrecht.

Chandran, S., 2003, Where are the ELT text books, SEAMO, Jurong.

Chimombo, J.P.G., 2005, 'Quantity versus quality in education: Case studies in Malawi', International Review of Education 55, 155-172. http://dx.doi.org/10.1007/ s11159-005-1842-8

Chisholm, L., 2005, 'The politics of curriculum review and revision in South Africa in regional context', in D. Naidoo (ed.), Educational theory and enquiry 2. Course reading pack, pp. 150-160, University of the Witwatersrand, Johannesburg.

Fredricks, A.D., 2005, Success as a teacher, Alpha books, Penguin Group Inc, New York.

Hammer, M., 2001, Advantages and Disadvantages of textbooks, New York Press, New York.

Hugo, W., Bertram, C., Green, W. \& Naidoo, D., 2008, 'Bernstein, Bloom and the analysis of pedagogy in South African schools', Journal of Education 43, 31-56.

Hutchinson, T. \& Torres, E., 1994, 'The textbook as agent of change', ELT Journal 48(4), 351. http://dx.doi.org/10.1093/elt/48.4.315

Jansen, J., 1998, 'A very noisy OBE: the implementation of OBE in grade 1 Classrooms', in J. Jansen \& P. Christie, Changing curriculum: Studies on outcomes-based education in South-Africa, pp. 40-50, Juta, Cape Town.

Kadzamira, E.C., 2006, Teacher motivation and incentives in Malawi, Centre for Education Research and Training, Zomba.

Khomani, P., 2005, Implementing the Malawi primary curriculum and assessment reform, Malawi Institute of Education, Domasi.

Kolb, D., 1994, Experiential learning: Experience as the source of learning and development, Prentice-Hall, New Jersey.

Lowe, I., 2008, 'Policy and practice in the teaching of mathematics education in the rural primary schools in Malawi', Unpublished PhD thesis, Monash University, Melbourne, viewed 12 Jan 2009, from http://arrow.monash.edu.au/hdl/1959.1/ 73686

Luykx, A., 1999, The citizen factory: Schooling and cultural production in Bolivia, State University of New York Press, New York.

Lukin, L.E., 2004, Materials evaluation, Edinburgh University Press, Edinburg, TX. 
Malawi Institute of Education, 2008a, Expressive Arts learners' book for standard 7, Malawi Institute of Education, Domasi.

Malawi Institute of Education, 2008b, Expressive Arts learners' book for standard 8, Malawi Institute of Education, Domasi.

Motara, S., 2002, 'The way teachers construe curriculum integration: The dichotomy of possibilities and constraints', Unpublished Masters' Research Report, University of Witwatersrand.

Muhamad, A., 2009, Analysis of teachers' use of English instructional materials: From preparation to implementation: A case of English instructional at STIA LAN Bandong, viewed 6 April 2015, from http://repository.upi.educ

Nsapato, L., 2005, 'Factors affecting the quality of basic education in Malawi', pape presented at the Malawi National Education Conference, Lilongwe, 24-26th March.

O'Neil, R., 1982, 'Why use textbooks?' ELT Journal 36(2), 104-111. http://dx.doi. org/10.1093/elt/36.2.104
Pederson, S., 2003 'Teachers' beliefs about issues in the implementation of a studentcentred learning environment', ETR\&D 51(2), 57-76. http://dx.doi.org/10.1007/ BF02504526

Richards, J.C., 2001, Textbooks: Evaluation for selection and analysis for implementation, University Press, Cambridge.

Sailors, M., 2012, 'Complementary Reading Material Development: Accomplishments, Successes and Challenges of the Read Malawi Programme', Botswana Journal of African Studies (Special Issue on Literacy) 26, 171-186.

Sheldon, L., 1988, 'Evaluating ELT textbooks and materials', ELT Journal 42(4), 237-246. http://dx.doi.org/10.1093/elt/42.4.237

Spady, W.G., 1994, Outcomes Based Education, Critical Issues and Answers, American Association of Social Administrators, Virginia.

UNESCO, 2000, 'Thematic studies', Textbooks and learning materials 1990-99, Paris, 7.

Ur, P., 1998, A course in language teaching: Practice and theory, Cambridge University Press, Cambridge. 